\title{
THE MASTER ARGUMENT AGAINST REALISM ${ }^{1}$
}

Metaphysical realism, let us assume for now, holds that much of the world is mind-independent and that truth is correspondence between thought and the world. Anti-realism is opposed to this. An important motivation driving anti-realism is an argument (or a family of arguments) to the effect that realism must inevitably succumb to global skepticism about the external world. This is the argument-with details to be filled in of course-that I will call the Master Argument Against Realism.

By way of leading up to the argument I have in mind, historically as well as systematically, consider the following often-quoted passage from Locke's Essay:

'Tis evident, the mind knows not things immediately, but only by the intervention of the ideas it has of them. Our knowledge, therefore, is real only so far as there is a conformity between our ideas and the reality of things. But what shall be here the criterion? How shall the mind, when it perceives nothing but its own ideas, know that they agree with things themselves? This, though it seems not to want difficulty, ..." (Locke, Essay IV.iv.3; my italics)

Locke continues with his account of how the difficulty he has identified is to be resolved-not too many readers were impressed, it seems. In any case, note that there is no hint of anti-realism in this passage or anywhere else in Locke. Note also the key occurrences of conformity and criterion. They are foreshadowings of things to come.

Things were coming fairly soon, with Berkeley arguing against Locke's realism, at times, it seems with the passage above very much on his mind. The Master Argument for Anti-Realism that I am building up to evolved from two of Berkeley's arguments. The first was (roughly): Realism is incoherent, because one cannot conceive a thing that is unconceived-later condensed into the notorious formula: No object without a subject. The second was: Realism leads to skepticism, because only ideas can resemble/be compared with ideas. These two arguments, fused together and elaborated a bit, eventually give rise to the Master Argument.

The core of this Master Argument Against Realism is nicely displayed in a passage by Kant. For preparation, consider first this sentence from Kant's Critique:

1 Precursors of this paper were presented at the 10th Congress of the Austrian Society for Philosophy, Innsbruck, Austria, June 5, 2015; and at the Department of Philosophy, University of Belgrade, December 7, 2015. My thanks to the audiences present for helpful comments. Special thanks to Chris Gauker, Johannes Brandl, Miloš Arsenijević, Jovan Babić, Duško Prelević, and Ljiljana Radenović. 
What is truth? The nominal definition of truth, that it is the agreement of [cognition] with its object, is assumed as granted; the question asked is as to what is the general and sure criterion of the truth of any and every [cognition]. (Kant, Critique A58/B82) ${ }^{2}$

Here is the main passage, to be found in Kant's Jäsche Logic:

Truth, it is said, consists in the agreement of cognition with its object. In consequence of this mere nominal explanation, my cognition, to count as true, is supposed to agree with its object. Now I can compare the object with my cognition, however, only by cognizing it. Hence my cognition is supposed to confirm itself, which is far short from being sufficient for truth. For since the object is outside me, the cognition in me, all I can ever pass judgment on is whether my cognition of the object agrees with my cognition of the object. The ancients called such a circle in explanation a diallelon. (Kant, Jäsche Logic, Introduction VII).

The passage actually covers only the first stage of the argument against realism: the ground is prepared, but the actual turn against realism is not executed (not yet). Kant brings up the correspondence theory of truth, and then questions the utility of correspondence as a criterion or test of truth ("my cognition, to count as true [um als wahr zu gelten], is supposed to agree with its object"); and he questions it radically: given that truth is correspondence with the world, he says, we can't have any knowledge of the external world. The import of the passage, as far as it goes, could be entirely skeptical.

However, the passage turns into an argument against realism, as soon as one adds to it the denial of skepticism, i.e., the premise that we can have knowledge of the external world. The denial of skepticism, then, constitutes the second stage of the argument, delivering, by modus tollens, the rejection of realism as its conclusion.

Note that the premise required for the turn against realism is not that we actually have knowledge of the external world. Since the first stage of the argument claims that, on the realist view, knowledge of the world would be impossible, all that is required for the second stage is: knowledge of the world is possible. Fittingly, the Master Argument thus takes the form of a transcendental argument against realism.

The second, anti-skeptical stage of the argument, executing the anti-realist turn, is of course crucial. Nevertheless, I will set it aside. The denial of skepticism is not where the action is in the debate between anti-realism and realism. That debate turns rather on the the issues mooted in the first stage of the argument, especially on the distinctive theme of "comparing" cognition (thought, belief) with its object (reality).

Here is my own version of the whole argument, containing both stages, with some terminology borrowed from Kant:

\section{The Master Argument Against Realism:}

We cannot step outside our own minds to compare our thoughts with mindindependent reality. Yet, on the realist correspondence view of truth, this is what we would have to do to gain knowledge of the world. We would have to access

2 This is the Kemp Smith translation, but I follow the practice of more recent translators and put 'cognition' in place of Kant's highly misleading 'Erkenntnis'. 
reality as it is in itself, to determine whether our thoughts correspond to it. Since all our access to the world is mediated by our cognition, this is impossible. Hence, on realism, knowledge of the world would be impossible. Since knowledge of the world is possible, realism must be wrong.

This formulation is a bit loose, which is deliberate. It is intended to capture a theme, a motif, recurring in anti-realist thought, especially in the traditional version of anti-realist thought: idealism. Actually, I tend to think that this theme is in fact the anti-realist leitmotif; that it has been (and still is) the strongest attractive force drawing people towards anti-realist positions, or making such positions seem tempting. I will not try to argue for this here. I hope you find it sufficiently compelling to stay with me. ${ }^{3}$

My aim in this paper is to identify some of the operative assumptions that enter into the Master Argument, especially into its first stage. I will not discuss them in very much detail - that would be on the agenda of a much larger project. Here, I just want to identify some of the main points that I suggest need looking after and to comment on them briefly.

\section{Truth and Realism}

Historically, correspondence theories of truth come in two versions: objectbased, and fact-based. An object-based version says, roughly: A judgment (belief) is true iff it corresponds with its object. This is the version we find in the passages quoted above from Kant. It actually invokes two mind-world relations: the relation of aboutness, holding between a judgment and some thing the judgment is about, making that thing the object of the judgment (its object); and, more noticeably, the relation of correspondence, holding between a true judgment and its object, which relation must be concerned with the predicate-part of the judgment and the properties of its object.

A fact-based version of the correspondence theory says: A judgment (belief) is true iff it corresponds with some fact. This is the more contemporary, Mooreand-Russell version of the theory. It explicitly invokes only one relation, also called "correspondence", holding between a true judgment (belief, thought) and an appropriately structured slice of reality, a fact.

Though the difference between the two versions is rarely taken notice of, it appears to be relevant to our topic. The relations called "correspondence" by the two versions are quite different, hence the pertinent comparisons differ. On the first version, the comparison would involve comparing the predicate-part of the judgment with the properties of the judgment's object. On the second version, it would involve comparing the judgment as a whole with a part of reality supposed to come appropriately structured as a fact. It might of course turn out that the difference is primarily a matter of metaphysical bookkeeping and will not make

3 In 1992, Anthony Brueckner published a paper entitled "The Anti-Realist's Master Argument". This paper is concerned with a Dummett-style argument, concerning the theory of linguistic meaning and evidence-transcendent truth-conditions. Times change. From the present perspective it seems that the more traditional argument outlined here never lost its title to being the master argument against realism. 
much of a difference in the end for how the discussion of the Master Argument plays out; but it is hard to tell, and there are indications that this may not be so. For one thing, the object-based version of the correspondence theory is severely limited: it applies, at best, only to subject-predicate judgments. Moreover, under the object-based version, the relation between a judgment and the object it is about (its object) is presupposed in the very statement of the problem concerning comparing (see Kant's statement of the problem in the passage from the Jäsche Logic above); consequently, attention will focus more narrowly on comparing predicates of judgments and properties of objects. This will play out differently under the more general, fact-based version of the correspondence theory, where attention will focus, obviously, on comparing whole judgments and facts.

Having pointed out the distinction between the two versions of the correspondence theory, I will gloss over it from now on (this is common practice), turning to a more general issue. The Master Argument assumes (or maybe better: those who wield the argument assume) that metaphysical realism is tied closely to the correspondence theory of truth (never mind the distinction between the two versions of the theory just mentioned):

Background Assumption: Realism is tied to the correspondence theory of truth.

This raises a terminological issue, concerning the proper use of the label "realism", as well as a substantive one, concerning the relation between the thesis of mind-independence (i.e. the thesis that much of the world is mind-independent) and the correspondence theory of truth. Take the substantive issue first.

Advocates of arguments along the lines of the Master Argument typically treat mind-independence and correspondence-truth as a package deal (if they distinguish them at all). Strictly speaking, this is wrong. Mind-independence does not imply a correspondence-truth: one can consistently embrace mindindependence and reject any form of correspondence theory. Advocates of deflationist theories of truth hold that truth has no nature and reject the correspondence theory, usually on the grounds that the notion of correspondence is defective in some way, or not scientifically respectable. Advocates of primitivism about truth reject the correspondence theory on the grounds that truth is not definable in any sense of the term. It would be hard going to try to show that such positions are, a fortiori, committed to the rejection of mindindependence.

Add to this the terminological issue. The label "realism" is often applied to the package of mind-independence and correspondence-truth. If so, the assumption above is not problematic and an argument targeting primarily correspondencetruth, such as the Master Argument, will obviously be an argument against realism thus defined. However, since mind-dependence does not really imply correspondence-truth, the alleged package is a mere conjunction, hence such an argument, while attacking realism thus defined, will not automatically attack the thesis of mind-independence. This is awkward, because it is the thesis of mindindependence that is the real target of most anti-realist argumentation-it is the real target of all idealist argumentation. If, on the other hand, the label "realism" 
is applied more narrowly, and by my lights more properly, namely to the thesis of mind-independence only, then the assumption above is false and the Master Argument Against Realism, since it proceeds by attacking correspondence-truth, is bound not to reach its target. What to do?

One might look into the question whether there can be (or whether there already is) an argument attacking realism that is recognizably similar to the Master Argument but does not proceed by attacking the correspondence theory of truth. This strikes me as potentially interesting, but I won't pursue it here.

It is not only the opponents of realism who have treated mind-independence and correspondence-truth as a package deal. Philosophers who have advocated mind-independence (or have taken it for granted) have typically also advocated some form of correspondence theory of truth (or have taken it for granted). Moreover, this is hardly a coincidence: mind-independence and the correspondence theory go together nicely, they make for a natural package. ${ }^{4}$ In view of the historical importance of this combination, it can be helpful for certain purposes, I think, to continue the (strictly speaking questionable) tradition and treat them as a package deal, which is what I am doing in this paper. Following a related (questionable) tradition, I will continue to use the label "realism" for the (alleged) package deal.

As an afterthought, I want to note that the correspondence theory of truth does not imply mind-independence either. This is easy to tell from the fact that one can advocate a position that conjoins the thesis of mind-dependence and a statement of the correspondence theory, e.g.: All facts are mind dependent; and a judgment (belief) is true iff it corresponds with some fact. Though this is not, strictly speaking, relevant to our topic, it is of some interest for our understanding of anti-realism in general-especially with a view to our understanding of Kant. Norman Kemp Smith (1923: 36) maintained "that Kant is the real founder of the Coherence theory of truth"; he did so in the face of Kant's express words to the contrary (see the passage above from the Critique where Kant says that the correspondence definition of truth is "assumed as granted" [wird hier geschenkt, und vorausgesetzt]). Apparently, Kemp Smith associated the correspondence definition so closely with realism that he could not see how this definition could fit into Kant's overall position and understood him as ultimately aiming to replace the correspondence theory with an anti-realist theory of truth. Another view of Kant, maybe historically more accurate, would see him as advocating a correspondence definition with an antirealist rider, similar to the view I just sketched a few lines above, only in his case it would be an object-based version:

4 Burnyeat (1982: 19) argues that idealism is "one of the very few major philosophical positions which did not receive its first formulation in antiquity". Idealism first arises in the time after Descartes, it is simply not an option for philosophers prior to the modern period, including the adherents of ancient skepticism. Consequently, talking about philosophers prior to the modern period, it is somewhat misleading to say that they "advocated" realism, mindindependence, and the correspondence theory. They did no such thing. They took these positions for granted. 
A judgment is true iff it corresponds with its object; where objects and properties are mind-dependent (in the transcendental sense). ${ }^{5}$

\section{Knowledge and Anti-Realism}

Still focusing on what I called the first stage of the Master Argument Against Realism, we can distinguish two parts within that stage of the argument:

Part A says that there is something we cannot do, namely compare our thoughts with reality to ascertain a correspondence between our thoughts and reality. (Can't Compare)

Part $B$ says that we have to do it, on a realist correspondence account of truth, if we are to obtain knowledge of the world. (Must Compare)

I will look at Part B first. The following line of reasoning seems to go into Part B: If truth is correspondence with reality, then, since knowledge requires truth, we have to know that our beliefs correspond with reality, if we are to know anything about reality.

A point of clarification. The intended claim here is not that I have to know the general proposition that my beliefs correspond with reality, in order to know anything about reality. The intended claim must be, rather, that with respect to any given belief of mine, I have to know of that belief that it corresponds with reality, in order for that belief to constitute a piece of knowledge. So, for example, the claim is: given that truth is correspondence with reality, to know that my shirt is grey, I have to know of my belief that my shirt is grey that it corresponds with reality.

But how, one should ask, does knowledge of the nature of truth enter into a necessary condition for knowledge of such humdrum matters as the color of my shirt? There is a double-move being made in the line of reasoning above. It starts, importantly, from the innocuous observation that knowledge requires truth (this brings truth into the picture), and then moves quickly, via Assumptions 1 and 2 (see below), to the lemma that, given realism, in order to know something, one needs to know of one's belief that it corresponds with reality.

Assumption 1: $S$ knows $p$, only if $S$ knows of her belief $p$ that it is true.

This is the first move. Note that it is not underwritten by the analysis of knowledge: " $S$ knows $p$, only if (i) $S$ believes $p$, (ii) $p$ is true, (iii)..." Knowledge does indeed require truth, but this point only yields the requirement that your belief has to be true to constitute a piece of knowledge (the innocuous point again), it does not yield the requirement that you also have to know, or even believe, that your belief is true.

Three counter-considerations seem especially pertinent; I present them dogmatically. First, there are subjects (small children, higher animals) who know

5 As to realism and the correspondence theory, note that realists have to resist the temptation to build mind-independence into the definition of truth, along the lines of: A judgment is true iff it corresponds with some mind-independent fact. Since mental states are not mind-independent, such a definition would, absurdly, imply that all judgments about mental states are untrue. 
things without having the conceptual resources to form meta-beliefs about the truth of their own beliefs. Second, acquisition of information comes through perception and reasoning; even with respect to subjects who are clearly in a position to form meta-beliefs about the truth of their own beliefs, perception and reasoning do not normally deliver, and certainly do not have to deliver, such meta-beliefs. Third, the assumption intimates that knowledge about the world can be acquired only via inference from known premises about the truth of one's own beliefs. This is quite implausible. Perceptual knowledge never works that way. Inferential knowledge might, in certain cases, but usually does not. (Note that even when you acquire knowledge through an informant known by you to be reliable, the meta-premise in play would be that her professed belief is true, not that your own belief is true.)

Assumption 2: If truth = correspondence with reality, then $S$ knows of her belief $p$ that it is true, only if $S$ knows of her belief $p$ that it corresponds with reality.

This is the second move. Assumption 1 functions to pave the way by bringing truth into the picture. Assumption 2 now aims to build on this and to bring in the realist account of the nature of truth. Of course, truth and its nature are in the picture already, in one way: since knowledge requires that your belief be true, it requires that your belief correspond with reality, given the correspondence account of truth. But our argument is not satisfied with this innocuous point (though having it in the background may help lending some credibility to the argument). Our argument wants to bring the nature of truth into the picture in an importantly different way: Assumptions 1 and 2 between them aim to put the nature of truth into the content of a knower's meta-belief.

Two main counter-considerations. First, Assumption 2 commits an intensional fallacy, similar to: Since $a=b, S$ knows that $a$ is $F$, only if $S$ knows that $b$ is $F$. Only in this case the fallacy involves a property identity: Since being $F$ = being $G, S$ knows of $a$ that it is $F$, only if $S$ knows of $a$ that it is $G$. Using this kind of reasoning, one might argue, fallaciously: Since water is $\mathrm{H}_{2} \mathrm{O}$, our ancestors knew that they were drinking water, only if they knew that they were drinking $\mathrm{H}_{2} \mathrm{O}$; and since they didn't know they were drinking $\mathrm{H}_{2} \mathrm{O}$, they didn't know that they were drinking water.

Second, the assumption fails to distinguish a (proposed) definition of truth from a process or procedure by which one comes to know that something is true. ${ }^{6}$ A definition of the nature of truth, an advocate of the correspondence theory will insist, does not have to provide a procedure for coming to know,

6 Revisit the beginning of the Kant passage from the Jäsche Logic, cited earlier, where Kant says that, in consequence oft he correspondence definition, his cognition "to count as true [um als wahr zu gelten], is supposed to agree with its object". Note the neat double function of the phrase "to count as true". Looking back at the definition, this can be read in the spirit of "to count as true by the lights of the definition", that is, as "to be true". Looking forward to his bringing up epistemic issues, it lends itself to be read as "to be rationally believed to be true". Read both ways at once, it serves to make an illegitimate transition from the definition of truth to epistemic matters concerning coming to know that something is true. 
and the correspondence account of the nature of truth does not. One can come to know that a liquid is water from the way it looks and tastes (etc.), one does not have to go through its $\mathrm{H}_{2} \mathrm{O}$-nature, performing a chemical analysis, to come to know that it is water. Similarly for truth. Though, admittedly, there is also a disanalogy, because going through the chemical analysis does provide one good way of coming to know that a liquid is water. This does not seem to be the case with the correspondence theory. How does one come to know of one's own belief $p$ that it is true? Here is one good way. First you come to know $p$. Then you reflect (for some reason) on your own beliefs, coming to believe and know that you have the belief $p$, then you infer that your belief $p$ is true, presupposing (exploiting, consciously?) your knowledge that $p$ entails that $p$ is true.

So far I have deliberately staved off the theme of comparing thought with reality, trying to get an idea about how much ground the Master Argument will cover without it. But now is the point where, it seems, the theme of comparing has to enter:

Assumption 3: S knows of her belief $p$ that it corresponds with reality, only if $S$ has compared her belief $p$ with reality.

Conclusion: If truth = correspondence with reality, $S$ knows $p$, only if $S$ has compared her belief $p$ with reality.

An initial point countering Assumption 3. Given that one can know of one's belief $p$ that it is true in the manner just described, one can know of one's belief $p$ that it corresponds with reality by knowing that one's belief $p$ is true and knowing the correspondence account of truth, without having to compare one's belief $p$ with reality.

Consider now the consequent of the Conclusion: $S$ knows $p$, only if $S$ has compared her belief $p$ with reality. As a general condition on knowledge, this should strike you as very strange. Much (most) acquisition of information does not proceed by comparing beliefs one already has with anything. Perceptual processes and inference processes do not proceed by comparing beliefs one already has, they proceed by forming beliefs which, under the right conditions, then constitute pieces of knowledge. Talk of "comparing" drops out of the picture when one thinks of how perception and inference based on perception lead to the formation of beliefs: for the most part, talk of "comparing" is just a bad metaphor.

Yet, Part B of the Master Argument nevertheless claims that realism, because it takes truth to be correspondence, is committed to the view that one knows, only if one has compared one's belief with reality. The reason for this claim being Assumptions 1 and 2, which harbor an intensional fallacy, the failure to distinguish definitions from descriptions of knowledge-acquisition processes, and an ill-motivated meta-knowledge requirement on knowledge.

However, the picture of knowing by comparing is not entirely wrong. Sometimes, it seems, we do compare, namely when we check the accuracy of beliefs we already have, when we test our beliefs or theories. Part B of the Master Argument, then, treats all coming to know as checking, all knowing as having 
checked. This is wrong, even if there are cases where one does know by checking one's beliefs-many cases, yet still very few, compared to the massive amount of cases where one acquires knowledge without checking.

I turn now briefly to the other part of the Master Argument, Part A. Remember it said that we cannot do what Part B said we have to do, namely compare our beliefs with reality (to ascertain their correspondence with reality).

Part A of the Master Argument focuses on comparing cognition (beliefs) with reality (facts, things and their properties). But its central claim seems to apply to comparing anything with anything: beliefs with facts, facts with facts, things with things, beliefs with beliefs (cognitions with cognitions). The central claim made by Part $\mathrm{A}$ is:

Can't Compare: We can never compare $X$ with $Y$, we can only compare our cognition of $X$ with our cognition of $Y$.

If taken seriously, this claim would launch an infinite regress, for obviously my cognition of $X$ and my cognition of $Y$ will themselves be new items, $X$ and $Y$, which, according to the claim, I can compare only by comparing my cognitions of these cognitions, and so on. The claim has to be restricted. The intended restriction must be to items that are not themselves cognitions, that is $X$ and $Y$ must not be cognitions. The Master Argument assumes, apparently, that we can compare our cognitions.

Let us grant the following claim for the sake of argument (keeping in mind that $X$ and $Y$ are not cognitions):

Compare Only: I can compare my cognition of $X$ with $Y$ only by employing a further cognition, namely a cognition of $Y$.

Even if this claim is true, it does not show that what I am comparing thereby is merely my cognition of $X$ with my cognition of $Y$. But this is the claim the Master Argument would need. Where does it come from? The situation is a bit odd. The above claim tells me that I can do one thing, A, only by doing another thing, B. And because of just this, I am supposed to accdept the strong negative conclusion that I cannot really do A after all, that I can merely do $A^{*}$, which is different from $\mathrm{A}$, and which is not what is wanted or needed. Yet, no further reason is in sight for this negative conclusion. Shouldn't I think, rather, that I can do A, and conclude from the claim above that the way to do it, apparently is by doing $B$ ?

\section{Truth Again: Psychologism?}

The correspondence theory of truth that has been presupposed throughout this paper-both versions of the theory distinguished earlier-applies truth to "judgments", "beliefs", "cognitions". This is problematic, for all these terms are ambiguous. Are they supposed to refer to mental states or activities (judging, believing, cognizing), or are they supposed to refer to their propositional contents (what is judged, what is believed, what is cognized)?

On the one hand, it seems that for the Master Argument to get off the ground, these terms, as employed in the correspondence definition of truth, 
have to refer to mental states or activities. For the argument says that we must, but can't, compare our mental states or activities with reality.

On the other hand, it seems that truth does not really apply to mental states or activities at all. It does not make sense to speak of a state of believing, or an act of judging or cognizing, as being true or false. What is true or false, rather, is what is believed or judged or cognized, i.e. the proposition that is the content of the state or act, and the proposition is not itself a mental state or act. A correct correspondence theory of truth, on this view, ought to be stated for propositions: A proposition is true iff it corresponds with a fact. The formulations of the correspondence theory presupposed by the Master Argument Realism are all seriously flawed, on this view. They all harbor the confusion that lies at the heart of Psychologism: confusing psychological states or acts with their non-psychological contents. According to this view, given a correct, nonpsychologistic form of the correspondence theory, comparing cognition with reality never enters the picture and the Master Argument Against Realism never gets off the ground.

Or does it?

\section{References}

Brueckner, Anthony (1992): “The Anti-Realist's Master Argument”, Midwest Studies in Philosophy 17.

Burnyeat, M. F. (1982): "Idealism and Greek Philosophy: What Descartes Saw and Berkeley Missed", in Godfrey Vesey (ed.), Idealism Past and Present (Royal Institute of Philosophy Lecture Series: 13), Cambridge University Press: Cambridge.

Kant, Immanuel (1781/1787): Critique of Pure Reason, translated by Norman Kemp Smith, St. Martin's Press: New York 1929.

Kant, Immanuel (1800): The Jäsche Logic, in: J. Michael Young (ed.), The Cambridge Edition of the Works of Immanuel Kant: Lectures on Logic, Cambridge University Press: Cambridge 1992.

Kemp Smith, Norman (1923): A Commentary to Kant's "Critique of Pure Reason", $2^{\text {nd }}$ edition; reprinted at the Humanities Press: Atlantic Highlands 1992.

Locke, John (1706): An Essay Concerning Human Understanding, edited by Roger Woolhouse, Penguine Books: London 1997. 